\title{
Childhood Liposarcoma
}

National Cancer Institute

\section{Source}

National Cancer Institute. Childhood Liposarcoma. NCI Thesaurus. Code C8091.

A rare malignant neoplasm arising from adipocytes, that occurs in children. The tumor maybe one of several histologic types including well-differentiated, dedifferentiated, myxoid/round cell, and pleomorphic liposarcoma. 